Theoretical and methodological article

\title{
Authorship, citations, acknowledgments, and visibility in social media: Symbolic capital in the multifaceted reward system of science
}

\author{
Nadine Desrochers* \\ École de bibliothéconomie et des sciences de l'information, Université de Montréal \\ PO Box 6128, Downtown Station, Montreal, Quebec, H3C 3J7 Canada \\ nadine.desrochers@umontreal.ca
}

Adèle Paul-Hus

École de bibliothéconomie et des sciences de l'information, Université de Montréal PO Box 6128, Downtown Station, Montreal, Quebec, H3C 3J7 Canada adele.paul-hus@umontreal.ca

Stefanie Haustein

École de bibliothéconomie et des sciences de l'information, Université de Montréal PO Box 6128, Downtown Station, Montreal, Quebec, H3C 3J7 Canada stefanie.haustein@umontreal.ca

Rodrigo Costas

Center for Science and Technology Studies (CWTS), Leiden University, P.O. box 905, 2300 AX Leiden, the Netherlands

Centre for Research on Evaluation, Science and Technology (CREST), Stellenbosch University, Private Bag X1, Matieland 7602, South Africa

rcostas@cwts.leidenuniv.nl

Philippe Mongeon

École de bibliothéconomie et des sciences de l'information, Université de Montréal PO Box 6128, Downtown Station, Montreal, Quebec, H3C 3J7 Canada

philippe.mongeon@umontreal.ca

Anabel Quan-Haase

Faculty of Information and Media Studies/Sociology, Western University, 1151

Richmond Street, London, ON, N6A 2B7, Canada

$+1-519-661-2111 \times 81405$ 
aquan@uwo.ca

Timothy David Bowman

Sociology of Education Research Center, RUSE

University of Turku, Finland 20014

School of Library and Information Science, Wayne State University, Detroit, MI, 48202, USA

timothy.d.bowman@wayne.edu

Jen Pecoskie

Independent Researcher, London Ontario, N5Y 4B1 Canada

jpecoskie@outlook.com

Andrew Tsou

Department of Information and Library Science, Indiana University, Bloomington, IN, 47405, USA

atsou@umail.iu.edu

Vincent Larivière

École de bibliothéconomie et des sciences de l'information, Université de Montréal PO Box 6128, Downtown Station, Montreal, Quebec, H3C 3J7 Canada vincent.lariviere@,umontreal.ca

*Corresponding author

\title{
Keywords
}

Acknowledgements, altmetrics, authorship, citation analysis, impact, inventorship, reward system of science, scholarly communication, social media, symbolic capital

\begin{abstract}
The reward system of science is undergoing significant changes, as traditional indicators compete with initiatives that offer novel means of disseminating and assessing scholarly impact. This paper considers a number of aspects of this reward system, including
\end{abstract}


authorship, citations, acknowledgements, and the growing use of social media platforms by academics, with an eye towards identifying contemporary issues relating to scholarly communication practices, as understood through the perspectives of Bourdieu's symbolic capital and Merton's recognition paradigms. This paper posits that, while scientific capital remains the foundation upon which the reward system of science is built, this system is revealing itself to be more and more multifaceted, extremely complex, and facing increasing tension between its traditional means of evaluation and the potential of new indicators in the digital era. The paper presents an extended literature review, as well as recommendations for further considerations and empirical research. A better understanding of the perceptions of academics would be necessary to properly assess the effects of these new indicators on scholarly communication practices and the reward system of science.

\section{Introduction}

Over the last decades, researchers' symbolic capital has become more visible, due to the growth in quantitative research evaluations. While researchers were historically evaluated using the holistic method of peer review performed by experts in their given field, these qualitative approaches are now combined with — or at times even replaced by - a plethora of quantitative indicators. This has led to an expanded visibility for the 
sociology of science, which has seemingly embraced the tenets of the evaluation society (Dahler-Larsen, 2013; Pontille, 2016).

Today, there are many offers at hand for the compiling and use of metrics for the evaluation of scholars. Indeed, quantitative indicators can be easily compiled based on data from platforms such as Google Scholar or ResearchGate, and with little effort. Because of the ease with which data can be gathered and compiled, there is a risk that haste and availability will cause users, experts or non-, to misinterpret the results obtained, or to give them inflated importance in certain contexts, leading to uneven or, worse, unfair evaluations. Given the massive increase of such platforms and of quantitative evaluations, scientists are increasingly aware of the "game". The term, "game", belongs to the Bourdieusian lens which shall be used here, but also to some of the risks now associated with the reward system of science as it stands. Indeed, researchers are not necessarily well-versed in how the current evaluation metrics might play out on their own path to consecration; as a result, they may turn to bibliometric "gaming" (such as the abuse of self-citations), and try to "play" the system by opting for creative but sometimes less-than-ethical ways of amassing symbolic capital, which obviously has an effect on the whole scientific system (Weingart, 2015). 
As discussed elsewhere by some of the authors of this paper (see Desrochers, Paul-Hus and Larivière, 2016), in the Bourdieusian lexicon, the "game" is crucial, for it is the core of the illusio, the set of rules that defines a given field and legitimizes its existence; it also identifies what is "of interest" to the "players" (or agents) of that field (Bourdieu, 1996: 227-228). Without considering the illusio, "we cannot understand symbolic capital, and the symbolic effects of capital"1 (Bourdieu, 2016: 864) Furthermore, the illusio defines the relationship between those who construct the habitus of the field; it reveals that, "the collusion of the agents [...] is the root of the competition which pits them against each other and which makes the game itself" (Bourdieu, 1996: 228). The text cited here is The Rules of Art, in which Bourdieu makes a point to oppose fields with loose codification structures (such as literature and art) to science, cited as a "highly-codified" field, and therefore with very strict rules in terms of the conditions of entry into the field, as well as the conditions of legitimation and consecration (Bourdieu, 1996: 226). In Homo Academicus, Bourdieu speaks of academic expectations as "based partly on a disposition to play the game and on investment in the game, and partly on the objective indeterminacy of the game" (1988: 89).

Elsewhere, Bourdieu (2001) described the sociology of science's "particular type of symbolic capital" as "a capital built on knowledge and recognition" (70; our translation

\footnotetext{
${ }^{1}$ Our translation of "on ne peut pas comprendre le capital symbolique, et les effets symboliques du capital [, sans réintroduire ce que j'appelle l'illusio]".
} 
of "une espèce particulière de capital symbolique, capital fondé sur la connaissance et la reconnaissance") and spoke of a "dialectic of acclaim and recognition" (1988: 83; the original French is slightly different: "la dialectique de la consécration et de la reconnaissance" [1984: 112]) It is interesting that the English word for the French "reconnaissance" is "recognition", a pillar of Merton's (1973) vision of the "reward system of science". Bourdieu (2001) admitted having been "unfair" at times towards Merton (31), due to his interpretation of the Mertonian framework as, to a certain extent, self-fulfilling, self-contained, and devoid of the struggles (luttes) inherent to Bourdieu's own vision the field (Bourdieu, 1975a, 1975b; in 2001: 28 as "l'enjeu des luttes"; in 2016: 814 as "luttes symboliques") and which oppose "social agents unevenly armed for these struggles"2 (2016: 816). This explains, at least in part, why Bourdieu does not perceive "recognition" and "symbolic capital" as mere equivalents, but as carriers, respectively, of "a different view of the scientific world"3 (2001: 28). However, if symbolic capital is a concept "that we can, broadly, identify for the time being with reputation, renown, celebrity"4 (Bourdieu, 2016: 119), then, together, and perhaps in their very tension, these two frameworks, Bourdieusian and Mertonian, provide sociologists with a Weltanschaunng that pervades the academic illusio today, perhaps

\footnotetext{
2 Our translation of "des agents sociaux inégalement armés pour ces luttes".

${ }^{3}$ Our translation. The French reads, "le fait de remplacer recognition par capital symbolique n'est pas un simple changement de lexique [...], mais induit une vision différente du monde scientifique".

${ }^{4}$ Our translation of "qu'on peut, en gros, identifier provisoirement à la réputation, la renommée, la célébrité",
} 
more than ever: to amass scientific capital in order to achieve legitimation and then consecration in the field through the production of knowledge and the recognition of this contribution by one's peers; this is indeed a "driving force of academic life", to one again use Cronin's (2005: 139) highly quotable turn of phrase. Furthermore, the relationship with the broader social field and the pressure for societal impact - and the importance of social capital, but also of "symbolic capital of external renown" (Bourdieu, 1998: 98) — may be gaining strength in view of the rising tide of altmetrics and public visibility now possible, and perhaps expected, or even demanded, of researchers.

In fact, while the scientific field may appear to be built upon a reward system seemingly unshakable and deeply rooted in tradition, and while it may cater to both an internal perception of its "rewards" as well as an external struggle in the social and political realms, recent developments have shown that its illusio is not unchanging. Propositions have been made, at various moments, to define the quintessential elements of the reward system of science, to adapt it to its time, or to propose new tools for the assessments it bestows. In some of his earlier work with Weaver-Wozniak, Cronin (1993) introduced a "reward triangle" of science: authorship, citations, and acknowledgments. During the decades that followed, he expanded on Merton and Bourdieu's frameworks, using them both at various times. His own work brought the notion of capital into the age of 
hyperauthorship, or "massive levels of coauthorship" (2001b: 558; see also Cronin 2014), as Cronin continued to work on the topics of "academic writing and its rewards", as the full title of his 2005 seminal work, The Hand of Science, attests. Cronin, at times with collaborators, anticipated altmetrics as metrics based on the "multiple modalities of signaling behavior which the Web affords" (Cronin et al., 1998: 1320; see also Cronin, 2001), establishing quite early that this would cause "shifting norms and practices in scholarly communication and evaluation" (Cronin, 1999: 953) and following up with early forays into the "bankable" (Cronin and Shaw, 2002: 1268) symbolic capital that could be afforded scientists by such measures as "Web hits, and media mentions", alongside citations (1267). It is therefore not surprising that previous and current work by some of the authors of this paper bring together Merton, Bourdieu, and Cronin (e.g. Desrochers, Paul-Hus and Larivière, 2016; Desrochers, Paul-Hus and Pecoskie, forthcoming).

If production of knowledge and peer recognition are still the pillars of academic impact, the surge in potential for visibility brought forth by the proliferation of social media is causing a shift in the illusio, with an enduring impetus to make knowledge evolve, but with a growing tension between the urges for science to respect its traditions, belong to its time, and look to the future. The scientific stakes (enjeux) inherent to the illusio may therefore be growing more complex than ever, spreading across the scientific and social 
fields in new ways. This imbrication may further ruffle scholars' perceptions of the types of symbolic capital, specifically scientific and more broadly social, required to become a consecrated agent of the field; it may also impact the ways in which scholars seek to amass these types of capital, thereby changing the way the game is played.

Changes bring about best practices and warnings, of course, and in 2015, Nature published The Leiden Manifesto for research metrics (Hicks et al., 2015) with 10 principles as a "distillation of best practice in metrics-based research assessment" (430) and as a plea by members of the scientific community for the contextualization and more responsible use of quantitative measures of productivity and impact. However, there is still work to be done in the implementation both of new tools and of their best uses, as well as an urgent need to ask the right questions of the right players.

Based on a review of the literature pertaining to the reward system of science, this paper seeks to examine the cycle of production and recognition of scientific communication, understood here as consisting of the following building blocks: authorship, citations, acknowledgements, and visibility in social media. This cycle therefore builds on the reward triangle, as proposed by Cronin and his collaborators, by considering the potential for scientific and social capital afforded by altmetrics as new forms of recognition — an outlook Cronin himself continued to put forth, namely as Editor-in- 
Chief of the Journal of the American Society for Information Science and Technology (e.g. Cronin, 2013a; 2013b), and as the co-editor, with Cassidy R. Sugimoto, of the collective work Beyond Bibliometrics: Harnessing Multidimensional Indicators of Scholarly Impact. In the first chapter of this book, which serves as its introduction (Cronin, 2014), and indeed throughout his career as a bibliometrician, Cronin relentlessly questioned the roles, relationships, and validity of various indicators, old, ignored, and new, within the existing reward system of science. In his own words, the

[c]hanges in the tools and platforms that support scholarly exchange and publication are giving rise to a new wave of metrics that can, with greater or lesser confidence, be used in research evaluation exercises, alongside more established (if still contested) indicators. (Cronin, 2014: 12)

This paper was conceptualized a collaborative effort in order to combine various specializations and see if a unified outlook could be constructed from shared and individual expertise. It has its roots in a panel presented at the annual conference of the American Society for Information Science and Technology (ASIST) in the fall of 2015 (Desrochers et al., 2016a). In September 2016, after this paper was submitted, a certain number of the authors also came together with other collaborators to present a fishbowl panel on the topic of the reward system of science at the International Conference on 
Science and Technology (STI; Desrochers et al., 2016b), in order to further the discussion within academia. This hence remains an ongoing conversation on topics of ongoing interest and concern.

\section{Authorship}

Authors and contributors

Authorship is at the core of the reward system of science as the "undisputed coin of the realm in academia; it embodies the enterprise of scholarship" (Cronin, 2001: 559). Paradoxically, there is no denying that "authorship", historically, has been a poorly defined concept in academia; Patel wrote in 1973 that "it is a moot question whether there exists any apparent consensus among authors on the criteria of awarding assistantship or coauthorship on the collaborators" (88); this remains true today even as authorship faces waves of change throughout academia (Cronin, 2015).

Authorship is also a multi-tiered form of scientific capital, since the position in the list of authors is often hierarchical (Zuckerman, 1968). Ordering practices vary across disciplines: alphabetical, rank by first position, rank by last position, rank by value given to specific tasks or contributions (Larivière et al., 2016), age or academic positions (Costas and Bordons, 2011), and sole authorship are all intrinsically associated to levels of recognition within disciplinary practices. This part of the illusio must 
therefore be understood and contextualized by those seeking to evaluate an author's contribution.

There are consensual aspects to authorship; for example, it does not automatically convey copyright in the classic sense. Instead, it provides recognition, or credit (Biagioli, 1998); and as strange as this could seem to an outsider, the very act of writing - quintessential to the attribution of "authorship" in other fields (such as creative literature) - is often expected, but not always required in science. Criteria may also differ between disciplines. Pontille's (2004) work on disciplinary practices revealed clear differences between fields where authors are typically writers (humanities, social sciences) and fields where they can be contributors of technical assistance (natural sciences and engineering; see also Biagioli, 2003). Conversely, the use of ghostwriters who fail to be acknowledged entirely has been more pronounced in medicine (LangdonNeuner, 2008; Sismondo, 2009); and lab contexts often lead to de facto authorship for the provider of the infrastructure, no matter the nature of their involvement, or lack thereof (Pontille, 2004).

Certain editorial associations have established guidelines and policies aimed at defining authorship through a series of "criteria" or have provided lists of the types of contributions that render one "eligible" to be listed as an author (International 
Committee of Medical Journal Editors, 2015; PLOS Journals, n.d.; see also Pontille, 2016). These policies can include guidance on the authorship attribution process, in that "the group ideally should decide who will be an author before the work is started and confirm who is an author before submitting the manuscript for publication" (International Committee of Medical Journal Editors, 2015). Increasingly, journals such as PLOS require a "statement on authorship" or "contribution declaration" for each submission, in which the corresponding author must provide details of each author's role (PLOS Journals, n.d.).

The main issue linked to the attribution of authorship, however, seems to reside less in providing undue credit than it does in failing to assign or accept responsibility, which authorship in science automatically conveys (Biagioli, 1998; Langdon-Neuner, 2008). The International Committee of Medical Journal Editors' (2015) criteria for authorship directly address this issue by stating that an author agrees to "be accountable for all aspects of the work in ensuring that questions related to the accuracy or integrity of any part of the work are appropriately investigated and resolved." Tracking the source of a mistake, or worse, fraud and misconduct, is much more difficult in a group (Biagioli, 1999; Kevles, 1998; Wray, 2006). It also allows a group to diffuse responsibility within its ranks (Mongeon and Larivière, 2016); as Rennie, Yank, and Emanuel (1997) pointed 
out, "the greater the number of coauthors, the less responsibility any will take for the whole" (580).

A reluctance to take responsibility for the parts of a collective work that were contributed by others is an interesting collective self-preservation behaviour, which testifies to the complexity of the illusio: contribution and responsibility are not equivalent currencies of symbolic capital, yet they converge in the authorship status. The ICMJE guidelines state that "Authors must meet all four conditions in order to be listed" (International Committee of Medical Journal Editors, 2015); PLOS is more nuanced in its requirements, having recently adopted the CRediT Taxonomy, a list of 14 types of contributions ranging from "Conceptualisation" to "Funding Acquisition", which can help identify the role of each author in large groups (PLOS Blogs, 2016; PLOS Journals, n.d.). This may work in medicine or other hard sciences, but can cause artificial restrictions in other disciplines and may be inapplicable in cases of collaborations between researchers who bring very different qualifications and levels of expertise to the project. The same can be said of interdisciplinary work, where diversity is one of the core assets of research. Here, the question of being able (and not just willing) to vouch for the validity and rigour of other scholars' work touches upon the very definition of collaboration; responsibility must then be defined in another way somewhere between illusio and, quite simply, trust. Whether this trust rests mainly on 
instinct, reputation (recognition through peer assessment or quantitative indicators), the validation of collaborators' methods, or just a reading of the final results remains a question to be asked.

\section{Inventorship}

It is widely acknowledged that science should contribute to economic growth, and commercialization of knowledge is sometimes referred to as the third mission of universities (Etzkowitz and Leydesdorff, 2000; Meyer, 2003). Obviously, this aspect of scientific endeavours positions the scientific field quite firmly in the broader political, economic, and social fields, as it conveys both scientific and a farther-reaching type of social capital to those who can claim to have made such contributions. Patents, for example, can be used as an indicator of the usefulness or the inventiveness of research (Meyer, 2003) and are often highly valued in faculty evaluation in those disciplines where applied research is frequent (e.g., engineering, computer sciences, and biomedical research). Being named an inventor on a patent is certainly a way to amass capital in these disciplines; however, patents operate first and foremost in the economic and legal realms, and these bring their own sets of governing principles and agents into play. Notably, not all scientific discoveries are patentable, and not all patentable ideas represent scientific discoveries (Packer and Webster, 1996). Patented discoveries must be useful (ruling out all basic knowledge and discoveries) and some things, such as 
living organisms, are not patentable according to intellectual property laws. Moreover, the concept of novelty is defined differently in the scientific and legal realms: novelty in science is based on the "partial truth of a specific scientific community", while the novelty of a patent claim is based on a "universalistic notion of a virtual community sharing a common stock of knowledge" (Packer and Webster, 1996: 436).

Nevertheless, there is an undeniable connection between the scientific and social fields where patents are concerned, especially in cases where the activities leading to the patented idea overlap with academic research. Previous investigations of cases where a research project yielded both papers and patents have shown that the number of authors is generally higher than the number of inventors, shedding light on the fact that practices and criteria of credit attribution in each realm differ radically (Haeussler and Sauermann, 2013). Inventorship, a status of recognition in the broader social and economic fields, is seemingly not as readily shared with all those who contributed to the project as the authorship status. This seems highlighted by the fact that only a select few cross over from academic recognition to social capital, as inventorship only rewards one specific kind of contribution (i.e. the conception of the invention), while diverse types of contributions (e.g. technical work and data collection) can be rewarded with authorship. For example, lab technicians who do not usually appear as inventors on patents can appear in a scientific article's author list. Another difference between 
authorship and inventorship is that the order in which the inventors are listed does not give any hints as to the status of the contributor or the level of contribution.

The particular type of social capital bestowed upon a patent's inventor therefore either challenges or complements the Mertonian ideals of communism and disinterestedness, depending on the point of view. One could argue that patents exist outside of academia and are therefore not submitted to these ideals. Conversely, the opposite view, whereby the social and scientific fields are intertwined more than ever in the double recognition of author and inventor gives weight to Bourdieu's view on scientific authority, including his stance that disinterestedness in science is mainly established in relation to the weight and nature of interest in other fields (1975b). Bourdieu illustrates the struggle for "distinctive, differential value of this particular type of social capital" that is associated with being known, by name, as the first to make a discovery, since the "scientist who makes the same discovery a few weeks or a few months later has been wasting his time" (1975b: 26). Bourdieu's language is harsh, but not entirely unrelated to the more lenient Mertonian stance on "originality" and "priority", as presented in the 1957 paper "Priorities in science discovery" (Merton, 1973) that portrays the "institution of science" as one that "defines originality as a supreme value and thereby makes recognition of one's originality a major concern" (Merton, 1973: 294). Due to this "major concern", Merton wrote at length on the issue of "multiples" or "similar 
discoveries having been made by scientists working independently of one another" (1973: 371) and called for the study of this phenomenon and of the contexts that see it emerges repeatedly in the history of science. No matter the level of contextualization, however, it is clear that the drive to be "first" is intrinsically linked to recognition and symbolic capital in academia.

Interestingly, the concept of inventorship is just as loosely defined as the concept of authorship, even within the legal realm, and patent laws do not contain clear criteria to determine inventor status. Instead, such criteria have been inferred from case law, and the literature it has yielded can be of use in understanding how such a status is "earned". According to an American judge ruling, "[t]he threshold question in determining inventorship is who conceived the invention... [i]nsofar as defining an inventor is concerned, reduction to practice, per se, is irrelevant" (In re Hardee, 223 USPQ 1122, 1123; Comm'r Pat. 1984). In addition, unlike the contributions to science of theoretical or methodological papers, for example, the simple formulation of desired or potential results is not an act of conception. The inventor must have discovered a non-obvious and concrete way to achieve the desired results (Ex parte Smernoff, 215 USPQ 545, 547; Bd. App. 1982). Clearly stated, inventors are responsible for the novelty and the non-obviousness of a patent claim. Determining inventorship thus requires being certain 
of who did what, but also having an irrefutable knowledge of the state of the art in the field at the moment of the patent application (Armstrong and Murphy, 2012).

The question regarding the value of a patent within the reward system of science therefore arises given that patenting and scientific research take place in different but overlapping fields, that some patentable results do not meet the criteria of publishable scientific discoveries, but that, conversely, some patents may offer reports on the same discoveries as scientific papers. Furthermore, it may be asked whether the scientific capital gained through inventorship should be considered only within the academic discipline concerned, or whether the broader social capital amassed by an inventor should then transcend disciplinary boundaries and have a higher value across academia than other types of outputs, such as papers (high codification) or blog posts (low codification).

\section{Citations}

Citations function as symbolic appraisal of previous knowledge claims and represent "pellets of peer recognition" (Merton, 1988: 620) within the scientific community. Over the last few decades, citations have increasingly been used to measure researchers' scientific impact and are central to the bibliometric toolbox. However, there is still an

ongoing debate about the meaning and value of citations (Cronin, 2016). More 
specifically, authors have highlighted the lack of a unified theory of the act of citing, which could support their use in research evaluation (Nicolaisen, 2007; Wouters, 1999).

An important milestone in the historical development and adoption of citations as a critical mark of symbolic capital in the reward system of science was the creation of the Science Citation Index (SCI) by Eugene Garfield in 1963. The development of such a database was critical for the use of citations in research evaluation, and created a clear contrast with other elements of the reward system, such as acknowledgements, which only started being indexed on a large scale in recent years. The SCI started with a rather communistic, in the Mertonian sense, foundational perspective: the relationships between documents, established by their cited references, mark an association of ideas and content; therefore, the relationships between citations allow for more efficient literature searches (Garfield, 1955). Over time, however, the SCI evolved from a filtering and information retrieval system into a tool for assessing the scientific impact of researchers, institutions, and countries based on the citations received by their publications. Bourdieu recognized its value, establishing "a score of more than five references in the Citation Index" as a valid criterion for "academic prestige" in his study of arts and social sciences faculty (1988: 76; in the original French, "prestige scientifique" [Bourdieu, 1984:101]); yet he also noted some of the biases and 
restrictions inherent to the Index, as well as to the uses of citations in general, all of which are still often alluded to today (see 1988: 83, 236 and below).

The SCI remained in a monopolistic position for most of its existence, but the last decade has seen the proliferation of new citation indexes, including the creation of Scopus by Elsevier and free tools such as Google Scholar or Microsoft Academic. All of these developments clearly highlight the central role of citations in the reward system of science; and just as authorship was described above as the "coin of the realm in academia" (Cronin, 2001: 559), citations have been called the "currency of science" (Wouters, 1999).

This role notwithstanding, the coverage and data quality of available citation indexes present challenging limitations, as alluded to above. For example, both the Web of Science and Scopus focus mainly on English-language journals; they also introduce a strong bias in favour of natural sciences and biomedical research, to the detriment of the social sciences and humanities (Hicks and Wang, 2011; Mongeon and Paul-Hus, 2016). These biases have an undeniable effect on the reward system of science, since they lead to the underrepresentation or even invisibility of scholars, particularly from non-English speaking countries and non-article-centred disciplines, where monographs, for example, might be highly regarded in traditional peer-review evaluations (such as most of the 
humanities). While Google Scholar, to name another source, has a much broader coverage, it represents a "black box", has low data quality, and does not provide users with the possibility of performing large-scale studies. Moreover, collecting and normalizing the data, which are necessary steps in creating appropriate citation indicators, are not possible with Google Scholar, and this undermines its validity and reliability as a source of data for bibliometric analyses (Wouters and Costas, 2012).

Nevertheless, the availability of large-scale data has led to highly sophisticated measurements of scientific impact and today, there are hundreds of citation-based indicators, some of which aimed at normalising for the effects of various dimensions (e.g., discipline, age of the documents, career stage, or funding obtained). The massive use of bibliometric indicators of outputs and impact for tenure and funding decisions has been associated with adverse - or even perverse - effects on researchers' publication practices (Haustein and Larivière, 2015). As noted above, the use of such indicators has affected the illusio and caused some scholars to change their publication strategies and to resort to "gaming" in order to optimise their profile ("salami slicing", shifts towards journals with a high Impact Factor, honorary authorships or citations, abuse of self-citations, perfunctory and so-called strategic citations, etc.). However, and despite the important limitations and intense criticism to which many of these indicators have been subjected - even within the bibliometric community - and despite the fact 
that there can be unfortunate readings of these indicators by the universities and government agencies that use them to assess the scientific impact of research, citationbased indicators such as the Journal Impact Factor and the h-index are still often synonymous with high amounts of symbolic capital, both in the scientific field and beyond (Haustein and Larivière, 2015).

The rise of the importance of citations further gives pause in terms of how scientific capital is allocated depending on the source used. One might ponder whether it is better to have published: a) a paper in a high Impact Factor journal such as Science or Nature but which has not been cited at all; b) an article in a low Impact Factor journal that has received more than 100 citations in the Web of Science; or c) an article in a journal not indexed in the Web of Science, but with more than 500 citations in Google Scholar. Somewhere amongst these indicators and sources, there is a symbolic-capital-related tension - or compromise. One might assume that the scientific capital associated with publishing in a prestigious journal would be immediate, especially given the fact that the potential for citations always remains, even if it is untapped as of yet; however, given the importance of citations and the various ways to count them, this may not be the perception of the academic community anymore. Along the same lines, it could be debated whether, today, it is better to have authored one paper with 40 citations or two papers with 20 citations each... or whether that, in certain fields, matters at all. 


\section{Acknowledgements}

Just as the underlying reasons to cite can be diverse, noble, or self-serving, the motivations to acknowledge the support of others can range from flattery and name dropping to the sincere or required demonstration of gratitude upon individuals, organizations, or funding agencies. Although acknowledgments can be perceived as a simple "scholar's courtesy" (Cronin, 1995), they can also be considered as markers of symbolic capital, since they are literally the public recognition of a contribution that led to the work's publication. Acknowledgements have been conceptualized as "supercitations" (Edge, 1979: 106), because the information they convey can reveal informal networks of collaboration and "trusted assessors" (Mullins and Mullins, 1973). In this sense, Mertonian norms can also be applied to acknowledgements in that they might be used and misused for purposes such as influencing the peer-review process, persuasion, and the perceived acquisition of recognition by association.

Cronin and his collaborators paved the way for the consideration of acknowledgments as potential indicators in the 1990s (Cronin, 1995; Cronin, McKenzie, and Rubio, 1993; Cronin and Overfelt, 1994; Cronin and Weaver-Wozniak, 1993). As mentioned above, acknowledgements are one of the three components of the reward triangle put forth by Cronin (1995; with Weaver-Wozniak, 1993). Compared to authorship and citations, 
however, acknowledgments are harder to interpret and assess and have therefore never been included in research evaluations, at least not formally. The ambiguous reputation of acknowledgments can be attributed in part to their lack of standardization: they vary greatly in nature, format, style, and position in the paper (first footnote, end paragraph, body of the text). Numerous researchers have highlighted the need for clearer norms and policies to inform the use of acknowledgments, prescribe their format, and define conditions for their inclusion (Brown, 2009; Chubin, 1975; McCain, 1991; Pontille, 2001; Rong, Grant and Ward, 1989). Similarly, the relationship between the acknowledging author and those acknowledged continues to be a subject of debate: whereas Cronin's 1995 survey of 272 US academics showed that most deemed it unnecessary to obtain written permission to thank named individuals, recent editorial policies have adopted the opposite stance. For example, the current submission guidelines of PLOS journals state that, "authors are responsible for ensuring that anyone named in the Acknowledgments agrees to be named" (PLOS journals, n.d.).

Even though acknowledgements have been the object of sustained interest in scholarly communication for the last 50 years, their value and functions within the reward system of science remain topics of discussion. In fact, analyses of the literature of the last decades (Desrochers, Paul-Hus, and Larivière, 2016; Desrochers, Paul-Hus, and Pecoskie, forthcoming) reveal persistent tensions between the perceptions of 
acknowledgments as genuine thanks or lip-service, sites of academic free expression or carefully worded requirements, consolation prizes for denying authorship or symbolic capital granted for task-related support (see also Desrochers, Paul-Hus, and Pecoskie, 2015). These limitations notwithstanding, acknowledgments have been, and continue to be, studied and assessed in a variety of disciplines, including sociology (e.g., Mackintosh, 1972), linguistics (e.g., Al-Ali, 2010), and bioinformetrics (Weber and Thomer, 2014), and approaches span the full range of quantitative and qualitative methods (see Desrochers, Paul-Hus, and Pecoskie, forthcoming, for an overview). Information provided by acknowledgment statements can reveal valuable contributions that did not reach authorship level (Paul-Hus et al., 2017); it can also reveal intellectual influences that could not be rewarded through formal citations. In that sense, acknowledgments can be perceived as potential markers of impact akin to, although different from, citations (Cronin, 1991; 2005); yet at this time, there seems to be little, if any, symbolic capital associated with them and they remain, in terms of academic rewards, a "courtesy".

However, the money trail has become a fundamental aspect of acknowledgement statements. In recent years, many journals — particularly in the biomedical field have required that all funding sources, including organization names and grant numbers, be disclosed in the acknowledgment section of a publication (e.g., Blood Journal, n.d.; 
$J A M A$, n.d.; The Lancet, n.d.). In 2008, new possibilities for the quantitative analysis of acknowledgements became available due to the Web of Science databases' massive indexation of the funding acknowledgement texts found in scientific articles. This new set of large-scale data led to a new wave of interest in acknowledgments, with studies investigating the impact of funding contributions on scientific publications (e.g., Lewison and Markusova, 2010; Lewison and Roe, 2012; Rigby, 2011, 2013; Wang and Shapira, 2011). It further led to a resurgence of interest in the study and consideration of acknowledgments within the reward system of science framework (e.g., Costas and van Leeuwen, 2012; Cronin, 2012; Dìz-Faez and Bordons, 2014). However, the evolving scope of the indexation of acknowledgements in Web of Science means that coverage varies greatly in terms of disciplines, specific databases, languages, types of publications, etc., and that great care should be taken in understanding exactly what is included in any given dataset (Paul-Hus, Desrochers and Costas, 2016). Furthermore, as stated above, one should always bear in mind that this indexing is first and foremost based in (and dependent on) the traces of funding, not invisible colleges and collaboration genealogies. The focus here is indeed on hard capital, with scientific and other types of social capital hitching their wagon to its tail. This is an interesting twist in the evolution of the system, given the aforementioned metaphors of authorship as coin (Cronin, 2001) and citations as currency (Wouters, 1999). As Cronin pointed out, in 
many cases, "media and metrics are co-constitutive" (2014: 13). This was already true of citation indexes and certainly warrants attention for acknowledgements as well.

\section{Visibility in social media}

\section{Output and presence}

Social media have been defined as "a group of Internet-based applications that build on the ideological and technological foundations of Web 2.0, and that allow the creation and exchange of User Generated Content" (Kaplan and Haenlein, 2010: 61). They include a variety of platforms aimed at diverse activities such as social networking, social bookmarking, blogging, microblogging, and wikis, as well as content sharing and reuse for videos, photos, data, software code, and other types of media.

Technological advances and access to information seem to be creating an environment where a scholar's online presence (a presence in the broader social field) should be considered alongside publication credit to determine productivity, impact, and overall value. Scholars are increasingly incorporating social media into their scholarly practices

(Gruzd, Staves, and Wilk, 2012; Quan-Haase, Martin, and McCay-Peet, 2015; van Noorden, 2014). Research blogs have developed as a new genre in scholarly communication and serve multiple functions, including the publication of informal, personal accounts of academic life, hosting discipline-specific debates, and acting as 
tools for social action (Clavel et al., 2015). In fact, increasing pressure on researchers by funding agencies, organizations, and universities to engage in the broader social field and, more specifically, to demonstrate societal impact has led scholars to turn to online environments to produce, consume, and disseminate information. This has, in turn, enabled the incorporation of online activities into scientific evaluations (Higher Education Funding Council for England, 2011; Piwowar, 2013; Viney, 2013; Wilsdon et al., 2015).

Besides maintaining existing connections and making new ones, researchers use social media to increase their visibility and that of their work, as well as to expand the reach of events, such as conferences, meetings, and workshops (Jeng, He, and Jiang, 2015, van Noorden, 2014). For example, Twitter is often used as a form of backchannel to engage audience members at conferences and to reach out to scholars who are not present (Quan-Haase, Suarez, and Brown, 2015; Reinhardt et al., 2009; Ross, Fountaine, and Comrie, 2012).

However, enthusiasm for scholarly exchanges via these tools varies greatly within disciplines (Quan-Haase, Suarez, and Brown, 2015), across disciplines (Holmberg and Thelwall, 2014; Tenopir, Volentine and King, 2013), and across platforms (e.g., Tenopir, Volentine, and King, 2013; van Noorden, 2014). The digital humanities offers 
an example of the full range of Twitter users, as it was observed that some users are hyperconnected, while others rely on the tool only sporadically, and others yet are nonusers (Quan-Haase, Martin, and McCay-Peet, 2015). In short, an important caveat here is scale: all told, only about $10 \%$ of researchers use Twitter for work; and tools geared specifically towards researchers (e.g. Mendeley, Slideshare, Academia.edu) are used less often still (Mas-Bleda et al., 2014; Tenopir, Volentine, and King, 2013; and see Sugimoto et al., forthcoming, for an overview of the current context,).

Furthermore, this new set of tools brings with it a new set of ethical considerations that may put a damper on scholars' enthusiasm. Acting in an unprofessional manner online or the misframing by an audience of a statement, image, or video as professional when the scholar intended it to be personal can have negative consequences for academic careers and reputations and, in extreme cases, lead to punishment or termination (Bowman, 2015). While scholars have traditionally been faced with the task of managing the boundaries between their personal and professional self-presentations (Goffman, 1959), scholars are now faced with much greater challenges as social networking sites can result in context-collapse (Marwick and Boyd, 2011). This brings new light to Bourdieu's statement that symbolic capital "is a very fragile capital"5 (2016: 133). Since scholars are using these tools both personally and professionally,

\footnotetext{
5 Our translation of "un capital très fragile".
} 
certain universities and other organizations have created social media use policies for their employees (Sugimoto et al., 2015) in order to protect themselves from potential problems. In such a context, scholars may reconsider their use of online tools; some create distinct social media accounts (Quan-Haase, Martin, and McCay-Peet, 2015), some leave social media altogether, and others make their accounts private in order to prevent their communications from being potentially misframed (not to mention replicated or stored; Bowman, 2015). For these and other reasons, such as those explained below, it is still unclear how scholars perceive production in social media in relation to symbolic capital in an academic context.

\section{Altmetrics}

Under the umbrella term "altmetrics" (Priem et al., 2010), events on social media are put forth as a means to capture more diverse forms of scholarly production and impact on audiences within and beyond academia. If social capital can be understood as power that can be accrued through connections in social networks, then it is clearly at the heart of social media platforms (Ellison, Steinfeld, and Lampe, 2007). The effects of online activities on the reward system of science were predicted by Cronin (2005), who wrote,

There will soon be a critical mass of web-based digital objects and usage statistics on which to model scholars' communication behaviors - publishing, 
posting, blogging, scanning, reading, downloading, glossing, linking, citing, recommending, acknowledging — and with which to track their scholarly influence and impact, broadly conceived and broadly felt. (196)

Altmetrics are generally understood as indicators of scientific production and recognition that are complementary or alternative to citations. Priem (2014) defined altmetrics as the "study and use of scholarly impact measures based on activity in online tools and environments" (266) and identified it as a subset of webometrics, but a more specific definition still eludes the literature. Haustein, Sugimoto, and Larivière (2015) have argued that,

[...] the heterogeneity and dynamicity of the scholarly communication landscape make a suitable umbrella term elusive. It may be time to stop labeling these terms as parallel and oppositional (i.e., altmetrics vs. bibliometrics) and instead think of all of them as available scholarly metrics with varying validity depending on context and function. (3)

Furthermore, Haustein, Bowman, and Costas (2016) introduced a conceptual framework that includes any type of "acts leading to (online) events" related to scholarly documents and agents. Altmetrics can therefore include such diverse metrics as 
Facebook likes, mentions in tweets, citations in blogs, and recommendations on F1000Prime, downloads, mentions in news outlets or policy documents, and library holdings (although some of these were available long before the idea of altmetrics was suggested). Accordingly, Haustein (2016) defined scholarly metrics as

[...] indicators based on recorded events of acts (e.g., viewing, reading, saving, diffusing, mentioning, citing, reusing, modifying) related to scholarly documents (e.g., papers, books, blog posts, datasets, code) or scholarly agents (e.g., researchers, universities, funders, journals). (416)

Despite the reigning vagueness surrounding social-media-based indicators, the fact remains that many platforms targeting researchers incorporate a type of reward system of their own through likes, shares, comments, recommendations, etc., and frequently emphasize the standing of users within and beyond the boundaries of this system (Jeng et al., 2015). For example, social networking platforms such as ResearchGate, Academia.edu, or Loop provide statistics that intend to combine traditional traces of production and recognition of academic achievements, such as publications and citations, with new ones, such as article and profile views, follower counts, or questions answered. Other platforms, such as ImpactStory or Kudos are entirely devoted to 
collecting metrics on research products (Piwowar, 2013), as well as boosting the visibility of researchers and their work.

Again, important considerations of scale and coverage need to be mentioned. Mendeley has been identified as the platform with the largest coverage of publications among the currently most frequently captured altmetrics: about $60 \%$ to $80 \%$ of recent journal articles have been saved to Mendeley (Costas, Zahedi, and Wouters 2015a; Mohammadi et al., 2015; Thelwall and Wilson, 2015; Zahedi, Costas, and Wouters, 2014). With its coverage of $10 \%$ to $20 \%$ of recent journal articles, Twitter represents the second-largest source of social media metrics (Costas, Zahedi, and Wouters, 2015a, 2015b; Haustein, Costas, and Larivière, 2015; Priem, Piwowar, and Hemminger, 2012). However, coverage rates were found to be higher for particular journals (Eysenbach, 2011) or arXiv preprints (Shuai, Pepe, and Bollen, 2012); and again, lower rates were found for papers from non-English speaking countries (Alperin, 2015; Maleki, 2014). The percentage of papers shared on Facebook is lower, around 5\%, and as few as $2 \%$ of recent journal articles covered in Web of Science are cited in blog posts (Haustein, Costas, and Larivière, 2015), while recommendations in F1000Prime are even more selective (Waltman and Costas, 2014). 
Furthermore, studies have largely focused on social media mentions of journal articles with a DOI and on their correlations with citations; this can be seen as a means to validate them as indicators of impact either different from or similar to citations. Altmetrics research has thus focused on the alternative reputation of traditional publication outputs and has largely neglected alternative forms of scientific production, such as original blog posts, published datasets, software code, and open review reports, arguably because the data is less readily available and uptake of alternative outputs is still slow.

The fact that the proportion of untweeted papers is three times as high as that of uncited papers further shatters the hopeful expectation that tweets could overcome citation delay (Haustein, Costas, and Larivière, 2015). With the exceptions of Mendeley reader counts (Li, Thelwall, and Giustini, 2012; Maflahi and Thelwall, 2015; Zahedi, Costas, and Wouters, 2014) and F1000 ratings (Li and Thelwall, 2012), which exhibit moderate positive relationships with citations, most social media metrics for journal articles show weak to non-existing correlations with citations (Costas, Zahedi, and Wouters, 2015a; Haustein, Costas, and Larivière, 2015; Priem, Piwowar, and Hemminger, 2012), suggesting that they reflect types of impact that differ from traditional forms of scientific capital as captured by citations. 
The majority of altmetrics studies have investigated the extent to which papers are present on various social media platforms and the frequency with which they are mentioned. Their findings have demonstrated the heterogeneity of metrics and variations between scientific disciplines: papers that have stronger connections to people's lives, such as health, environmental, or social science research, were found to be more popular on social media than papers pertaining to natural sciences or engineering (e.g., Costas, Zahedi, and Wouters, 2015a, 2015b; Haustein, Costas, and Larivière, 2015). This could mean that the type of capital associated with this form of impact may indeed be more broadly social than strictly scientific; yet social media metrics lack more qualitative investigations into their underlying processes, since their validity as measures of societal impact or social capital is far from proven (Haustein, 2016). Nevertheless, altmetrics are affecting the reward system of science, as more publishers display them and more researchers implement them into their curriculum vitae (Piwowar and Priem, 2013). This may have a concrete effect on the illusio and on how scholars are rewarded, funded, or promoted in the future; but once again, it is unclear whether engaging in social media actually adds to a scholar's symbolic capital, and how this part of the game will play out remains to be seen.

\section{Conclusion}


As quantitative and web-based indicators increase in number and scope, the reward system of science is indeed undergoing the significant change announced by such bibliometricians as Blaise Cronin as early as the 1990s. Today, the various agents of the field have no choice but to try to make sense of and integrate the myriad new forms of engagement on social media with traditional indicators of production and impact such as authorship and citations, along with the types of traces afforded by the new large-scale data on acknowledgements. David Pontille (2016) recently wrote that, "the notion of scientific contribution reveals itself to be multiple, declined, diffracted"6 (182), and taking a page from his book is certainly relevant here, given the tensions created in the academic field by the implementation of web-based measures, or at times even just by the presence and pressure to adopt and make use of web-based platforms.

By examining the literature through the lenses of the Mertonian reward system of science and the Bourdieusian concepts of symbolic capital and illusio, this paper posits that while recognition and scientific capital remain the foundations upon which the reward system of science is built and the academic field operates, this system is revealing itself to be more and more multifaceted, extremely complex, and facing increasing tension between its traditional means of evaluation and the potential of new indicators in the digital era. Needless to say, such complexity brings challenges that can

${ }^{6}$ Our translation of "la notion de contribution scientifique s'avère multiple, déclinée, diffractée". 
affect how scholarly communication practices will evolve and how impact will be defined, measured, and - perhaps most importantly — contextualized in the everevolving academic field. Obviously, the Merton-Bourdieu lens is but one framework through which the field can be observed, studied, and understood. Scholars such as Blaise Cronin, and others still offer distinctive points of view on "academic writing and its rewards" (Cronin, 2005) — given the contents of this paper, one might say "academic life and its rewards". Yet, as Cronin himself put it, "for some of us Mertonianism continues to offer a suave theoretical framework that melds institutional with individual motivations" (2005: 6); and he, too, continued to use Bourdieu's work to support his own claim to - in his unique tongue-in-cheek way — "increase [his] stock of symbolic capital" (2005: 6).

We are in a time where, to borrow once more from Cronin, "with new-age metrics come age-old concerns" (2014:14). The conceptual framework chosen here offers an opportunity to look back on time-honoured values of academia such as a certain idealism in the advancement and sharing of knowledge, the dynamics of personal ambition and competition within (or in contradiction with) this idealism, responsibility, collaboration, disciplinary habitus and guidelines for best practices. These values are all contingent on the basic view of an academic system built on the cornerstone of a community of peers which bestows and esteems recognition as its main recompense, 
reward, currency, capital, or honour. It allows for the continued discussion of what Merton (1973) has called the "tension between [...] kindred values" in certain scientists (305) that can lead to what he described elsewhere as a "painful contrast" in expected and actual behaviour (1973: 393); and while Merton was referring to the "ambivalence towards priority" (1973: 305), it is certainly possible to argue that this tension extends to other forms of capital-amassing activities.

Despite the apparent highly codified legitimation and consecration mechanisms of the field, Bourdieu stated that "We know, however — and it is one of the most revealing characteristics of this field which claims to recognize only scientific values - that there is no such thing, or hardly any such thing, as a genuine institutional criterion of scientific value" (1988: 297). While this may seem like a sweeping statement, there is a sense of truth to it, albeit an uneasy one; and if nothing else, it can be turned into a question that remains relevant in the current context.

Indeed, today, the literature pertaining to the various components of the current reward system of science seems to be converging upon warnings and best practices that are oftsuggested, but not always observed: the undeniable question of biases in the data (and databases) used for bibliometric studies; data sources and data quality; the need for disciplinary, cultural, linguistic, and economic contextualisation; the need for more 
complementary uses of quantitative and qualitative analyses; and the relatively small representation of academics or papers on platforms being hailed as new potential sources for evaluation.

Current practices suppose that academics are in favour of a two-pronged approach to evaluation in which quantitative measures are used in combination with qualitative assessments. However, at this juncture, it seems that the large-scale data that is missing is the one pertaining to the actual perceptions and opinions of academics on this topic, across disciplines, as well as across socio-cultural and linguistic contexts.

This suggests that surveying academics, as well as non-academics in closely related fields (and perhaps even policy makers), on how they currently perceive the reward system of science and the academic field in general, as well as what value they impart to their different building blocks in terms of recognition and symbolic capital is overdue. This would lead to a better understanding of the potential repercussions the changes in the reward system of science might be having on the way capital is awarded and recognized and, ultimately, to positive changes in the game.

\section{Acknowledgements}


This research was supported by the Social Sciences and Humanities Research Council of Canada, Insight Development [grant number 430-2014-0617], Larivière and Desrochers; Insight [grant number R3603A13], Quan-Haase; Joseph-Armand Bombardier CGS Doctoral Scholarships, Paul-Hus; by the Fonds de recherche du Québec - Société et culture, Paul-Hus; by funding from the South African DST-NRF Centre of Excellence in Scientometrics and Science, Technology and Innovation Policy (SciSTIP), Rodrigo Costas; as well as the Alfred P. Sloan Foundation [grant number G2014-3-25], Haustein and Larivière. The authors wish to thank the participants in the panel that took place at the ASIST's 2015 Annual Conference; while the results of the survey were not included in the paper, due to the small size of the sample, their participation helped further our reflection and increase our belief in the need for more research into current perceptions by academics as to what matters in academia. The same gratitude goes out to those who attended or spoke up at the STI fishbowl, whether they agreed with our outlook or not; such open discussions with, and feedback from, colleagues are certainly another "driving force" to pursue this type of work.

\section{References}

Al-Ali MN (2010) Generic patterns and socio-cultural resources in acknowledgements accompanying Arabic Ph.D. dissertations. Pragmatics 20(1): 1-26. 
Almind TC and Ingwersen P (1997) Informetric analyses on the World Wide Web: Methodological approaches to 'webometrics'. Journal of Documentation 53(4): 404426.

Alperin JP (2015) Geographic variation in social media metrics: An analysis of Latin American journal articles. Aslib Journal of Information Management 67(3): 289-304. Armstrong N and Murphy E (2012) Conceptualizing resistance. Health 16(3): 314-326.

Biagioli M (1998) The instability of authorship: Credit and responsibility in contemporary Biomedicine. FASEB Journal 12(1): 3-16.

Biagioli M (1999) The science studies reader. Psychology Press.

Biagioli M (2003) Rights or rewards. In: Biagioli M and Galison P (eds) Scientific Authorship: Credit and Intellectual Property in Science. Routledge, pp. 253-279.

Blood Journal (n.d.) Author Guide - Editorial Policies for Authors. Available at: http://www.bloodjournal.org/page/authors/author-guide/Editorial-policies-for-authors (accessed 9 August 2016).

Bourdieu P (1975a) La spécificité du champ scientifique et les conditions sociales du progrès de la raison. Sociologies et sociétés 7(1): 91-118.

Bourdieu P (1975b) The specificity of the scientific field and the social conditions of the progress of reason. Social Science Information 14(6): 19-47.

Bourdieu P (1984) Homo academicus. Paris: Les Éditions de Minuit.

Bourdieu P (1988) Homo Academicus. Stanford, CA: Stanford University Press. 
Bourdieu P (1996) The Rules of Art: Genesis and Structure of the Literary Field. Stanford, CA: Stanford University Press.

Bourdieu, P (2001) Science de la science et réflexivité. Paris: Éditions Raisons d'agir.

Bourdieu P (2016) Sociologie générale, volume 2: Cours au Collège de France, 19831986. Paris: Éditions Raisons d'agir/Éditions du Seuil.

Bowman TD (2015) Differences in personal and professional tweets of scholars. Aslib Journal of Information Management 67(3): 356-371.

boyd d (2006) Friends, Friendsters, and top 8: Writing community into being on social network sites. First Monday.

Brown R (2009) How scholars credit editors in their acknowledgements. Journal of Scholarly Publishing 40(4): 384-398.

Chubin DE (1975) Trusted assessorship in science: A relation in need of data. Social Studies of Science 5(3): 362-367.

Clavel P, Fox K, Leo C, Quan-Haase A, Saitta D and LaDale W (2015) Blogging the city: Research, collaboration, and engagement in urban e-planning. Critical notes from a conference. International Journal of E-Planning Research (IJEPR) 4(1).

Costas R and Bordons M (2011) Do age and professional rank influence the order of authorship in scientific publications? Some evidence from a micro-level perspective. Scientometrics 88(1): 145-161 
Costas R and van Leeuwen TN (2012) Approaching the "reward triangle": General analysis of the presence of funding acknowledgments and "peer interactive communication" in scientific publications. Journal of the American Society for Information Science and Technology 63(8): 1647-1661.

Costas R, Zahedi Z and Wouters P (2015a) Do "altmetrics" correlate with citations? Extensive comparison of altmetric indicators with citations from a multidisciplinary perspective. Journal of the Association for Information Science and Technology 66(10): 2003-2019.

Costas R, Zahedi Z and Wouters P (2015b) The thematic orientation of publications mentioned on social media: Large-scale disciplinary comparison of social media metrics with citations. Aslib Journal of Information Management 67(3): 260-288.

Cronin B (1991) Let the credits roll: A preliminary examination of the role played by mentors and trusted assessors in disciplinary formation. Journal of Documentation 47(3): $227-239$.

Cronin B (1995) The Scholar's Courtesy: The Role of Acknowledgement in the Primary Communication Process. Taylor Graham.

Cronin B (1999) The Wharholian moment and other proto-indicators of scholarly salience. Journal of the American Society for Information Science and Technology 50(10): 953-955. 
Cronin B (2001a) Bibliometrics and beyond: Some thoughts on web-based citation analysis. Journal of Information Science 27(1): 1-7.

Cronin B (2001b) Hyperauthorship: A postmodern perversion or evidence of a structural shift in scholarly communication practices? Journal of the American Society for Information Science and Technology 52(7): 558-569.

Cronin B (2005) The Hand of Science: Academic Writing and its Rewards. Scarecrow Press.

Cronin B (2013a) Editorial: Metrics à la mode. Journal of the Association for Information Science and Technology 64(6): 1091.

Cronin B (2013b) Editorial: The evolving indication space (iSpace). Journal of the Association for Information Science and Technology 64(8): 1523-1525.

Cronin B (2014) Scholars and scripts, spoors and score. In: Cronin B and Sugimoto CR (eds) Beyond Bibliometrics: Harnessing Multidimensional Indicators of Performance. Cambridge, MA: MIT Press, pp. 3-21.

Cronin B (2015) The writing on the wall. Journal of the Association for Information Science and Technology 66(5): 873-875.

Cronin B (2016) The incessant chattering of texts. In: Sugimoto CR (ed) Theories of Informetrics and Scholarly Communication. A Festschrift in Honor of Blaise Cronin. Berlin: De Gruyter, pp. 13-19. 
Cronin B and Overfelt K (1994) Citation-based auditing of academic performance. Journal of the American Society for Information Science 45(2): 61.

Cronin B and Shaw D (2002) Banking (on) different forms of symbolic capital. Journal of the American Society for Information Science 53(14): 1267-1270.

Cronin B and Weaver-Wozniak S (1993) Online access to acknowledgements. In Proceedings of the 14th National Online Meeting 1993. New York: M.E. Williams, pp. 93-98.

Cronin B, McKenzie G and Rubio L (1993) The norms of acknowledgement in four humanities and social sciences disciplines. Journal of Documentation 49(1): 29-43.

Cronin B, Snyder HW, Rosenbaum H, Martinson A and Callahan E (1998) Invoked on the Web. Journal of the American Society for Information Science 49(14): 13191328.

Dahler-Larsen P (2013) Evaluation as a situational or universal good? Scandinavian Journal of Public Administration

Desrochers N, Haustein S, Alperin JP, et al (2016b). The reward (eco)system of science: More than the sum of its parts? In Ràfols I, Molas-Gallart J, Castro-Martínez E and Wolley R (ed) Proceedings of the 21st International Conference on Science and Technology Indicators, València (Spain), September 14-16, 2016: 477-484. Available at http://ocs.editorial.upv.es/index.php/STI2016/STI2016/paper/viewFile/4543/2327 
Desrochers N, Paul-Hus A, Bowman T, et al (2016) Authorship, patents, citations, acknowledgments, tweets, reader counts and the multifaceted reward system of science. In Proceedings of the American Society for Information Science and Technology 52(1): 1-4. DOI: 10.1002/pra2.2015.145052010013

Desrochers N, Paul-Hus A and Larivière V (2016) The angle sum theory: Exploring the literature on acknowledgments in scholarly communication. In: Sugimoto CR (ed): Theories of Informetrics and Scholarly Communication. A Festschrift in Honor of Blaise Cronin. Berlin: De Gruyter.

Desrochers N, Paul-Hus A and Pecoskie J (2015) Founding concepts and foundational work: Establishing the framework for the use of acknowledgments as indicators. Proceedings of the 15th International Conference on Scientometrics and Informetrics, International Society for Scientometrics and Informetrics (ISSI)

Desrochers N, Paul-Hus A, and Pecoskie J (Forthcoming) Five decades of gratitude: A meta-synthesis of acknowledgements research. Journal of the Association for Information Science and Technology.

Dìaz-Faes AA and Bordons M (2014) Acknowledgments in scientific publications: Presence in Spanish science and text patterns across disciplines. Journal of the Association for Information Science and Technology 65(9): 1834-1849.

Edge D (1979) Quantitative measures of communication in science: A critical review. History of Science 17: 102-134. 
Ellison NB, Steinfield C and Lampe C (2007) The benefits of Facebook "friends:"

Social capital and college students' use of online social network sites. Journal of

Computer-Mediated Communication 112(4).

Etzkowitz H and Leydesdorff L (2000) The dynamics of innovation: From national systems and "Mode 2" to a triple helix of university-industry-government relations. Research Policy 29(2): 109-123.

Eysenbach G (2011) Can tweets predict citations? Metrics of social impact based on Twitter and correlation with traditional metrics of scientific impact. Journal of Medical Internet Research 13(4): e123.

Garfield E (1955) Citation indexes for science. A new dimension in documentation through association of ideas. Science 122: 108-111.

Goffman, E (1959) The Presentation of Everyday Life. New York: Anchor Books.

Gruzd A, Staves K and Wilk A (2012) Connected scholars: Examining the role of social media in research practices of faculty using the UTAUT model. Computers in Human Behavior 28(6): 2340-2350.

Gu F and Widén-Wulff G (2011) Scholarly communication and possible changes in the context of social media: A Finnish case study. The Electronic Library 29(6): 762776. 
Haeussler C and Sauermann H (2013) Credit where credit is due? The impact of project contributions and social factors on authorship and inventorship. Research Policy 42(3): 688-703.

Haustein S (2016) Grand challenges in altmetrics: heterogeneity, data quality and dependencies. Scientometrics 108(1): 413-423.

Haustein S and Larivière V (2015) The use of bibliometrics for assessing research: Possibilities, limitations and adverse effects. In Welpe IM, Wollersheim J, Ringelhan $\mathrm{S}$ and Osterloh M (eds) Incentives and Performance: Governance of KnowledgeIntensive Organizations. Springer, pp. 121-139.

Haustein S, Bowman TD and Costas R (2016) Interpreting "altmetrics": viewing acts on social media through the lens of citation and social theories. In: Sugimoto CR (ed): Theories of Informetrics and Scholarly Communication. A Festschrift in Honor of Blaise Cronin. Berlin: De Gruyter, pp. 372-405.

Haustein S, Costas R and Larivière V (2015) Characterizing social media metrics of scholarly papers: The effect of document properties and collaboration patterns. PLoS ONE 10(3): e0120495.

Haustein S, Larivière V, Thelwall M, Amyot D and Peters I (2014) Tweets vs. Mendeley readers: How do these two social media metrics differ? IT-Information Technology 56(5): 207-215. 
Haustein S, Peters I, Sugimoto CR, Thelwall M and Larivière V (2014) Tweeting biomedicine: An analysis of tweets and citations in the biomedical literature. Journal of the Association for Information Science and Technology 65(4): 656-669.

Haustein S, Sugimoto CR and Larivière V (2015) Social media in scholarly communication. Aslib Journal of Information Management 67(3): 1-14.

Herman B (2014, September 5) Steven Salaita Twitter scandal: University offers settlement, but free speech questions linger. International Business Times.

Hicks D and Wang J (2011) Coverage and overlap of the new social sciences and humanities journal lists. Journal of the American Society for Information Science and Technology 62(2): 284-294.

Hicks D, Wouters P, Waltman L, de Rijcke S and Rafols I (2015) Bibliometrics: The Leiden manifesto for research metrics. Nature 520: 429-431.

Higher Education Funding Council for England (2011) Decisions on assessing research impact. Research Excellent Framework (REF) 2014 (Research Excellence Framework No. 01.2011). Available at:

http://www.ref.ac.uk/media/ref/content/pub/decisionsonassessingresearchimpact/01 11.pdf (accessed 9 August 2016).

Holmberg K \& Thelwall M (2014) Disciplinary differences in Twitter scholarly communication. Scientometrics 101(2): 1027-1042. 
International Committee of Medical Journal Editors (2015) Recommendations for the conduct, reporting, editing, and publication of scholarly work in medical journals. Retrieved from http://www.icmje.org/icmje-recommendations.pdf

JAMA (n.d.) JAMA instructions for authors - Acknowledgements section. Retrieved from

http://jama.jamanetwork.com/public/instructionsForAuthors.aspx\#AcknowledgmentS ection

Jeng W, DesAutels S, He D and Li L (2015) Information exchange on an academic social networking site: A multi-discipline comparison of ResearchGate Q\&A. arXiv preprint arXiv:1511.03597. Available at: http://arxiv.org/pdf/1511.03597.pdf (accessed 9 August 2016).

Jeng W, He D and Jiang J (2015) User participation in an academic social networking service: A survey of open group users on Mendeley. Journal of the Association for Information Science and Technology 66 (5): 890-904.

Kaplan AM and Haenlein M (2010) Users of the world, unite! The challenges and opportunities of Social Media. Business Horizons 53(1): 59-68.

Kevles D (1998) The Baltimore Case: A Trial of Politics, Science, and Character. W.W. Norton \& Co., New York.

Langdon-Neuner E (2008) Medical ghost-writing. Mens Sana Monographs 6(1): 257. 
Larivière V, Desrochers N, Macaluso B, Mongeon P, Paul-Hus A. \& Sugimoto CR (2016) Contributorship and division of labor in knowledge production. Social Studies of Science 46(3): 417-435. DOI: 10.1177/0306312716650046

Lewison G and Markusova V (2010) The evaluation of Russian cancer research. Research Evaluation 19(2): 129-144.

Lewison G and Roe P (2012) The evaluation of Indian cancer research, 1990-2010. Scientometrics 93(1): 167-181.

Li X and Thelwall M (2012, September) F1000, Mendeley and traditional bibliometric indicators. In Proceedings of the 17th international conference on science and technology indicators (Vol. 2, pp. 451-551).

Li X, Thelwall M and Giustini D (2012) Validating online reference managers for scholarly impact measurement. Scientometrics 91(2): 461-471.

Mackintosh SH (1972) Acknowledgment patterns in sociology.

Maflahi N and Thelwall M (2015) When are readership counts as useful as citation counts? Scopus versus Mendeley for LIS journals: When are readers as good as citers for bibliometrics? Scopus vs. Mendeley for LIS Journals. Journal of the Association for Information Science and Technology.

Maleki A (2014) Networking in science tweets linking to scholarly articles of Iran. Presented at the SIG/MET Workshop, ASIS\&T 2014 Annual Meeting, Seattle. 
Available at: http://www.asis.org/SIG/SIGMET/data/uploads/sigmet2014/maleki.pdf (accessed 9 August 2016).

Marwick AE and boyd d (2011) I tweet honestly, I tweet passionately: Twitter users, context collapse, and the imagined audience. New Media \& Society 13(1): 114-133. DOI: $10.1177 / 1461444810365313$

Mas-Bleda A, Thelwall M, Kousha K and Aguillo IF (2014) Do highly cited researchers successfully use the social web? Scientometrics 101(1): 337-356.

McCain KW (1991) Mapping economics through the journal literature: An experiment in journal cocitation analysis. Journal of the American Society for Information Science 42(4): 290.

Merton RK (1973) The Sociology of Science: Theoretical and Empirical Investigations. Chicago, IL: Chicago University Press.

Merton RK (1988) The Matthew effect in science, II: Cumulative advantage and the symbolism of intellectual property. Isis 79: 606-623.

Meyer KA (2003) The Web's impact on student learning. The Journal 30(10).

Meyrowitz J (1990) Redefining the situation: Extending dramaturgy into a theory of social change and media effects. In: Beyond Goffman: Studies on Communication, Institutions, and Social Interaction. New York, NY: Mouton de Gruyter, pp. 65-97. 
Mohammadi E, Thelwall M, Haustein S and Larivière V (2015) Who reads research articles? An altmetrics analysis of Mendeley user categories. Journal of the Association for Information Science and Technology 66(9): 1832-1846.

Mongeon P and Larivière V (2016) Costly Collaborations: The Impact of Scientific Fraud on Co-Authors' Careers. Journal of the Association for Information Science and Technology 67(3): 535-542.

Mongeon P and Paul-Hus A (2016) The journal coverage of Web of Science and Scopus: A comparative analysis. Scientometrics 106(1): 213-228.

Mullins NC and Mullins CJ (1973) Theories and Theory Groups in Contemporary American Sociology. New York: Harper and Row.

Nicolaisen J (2007) Citation analysis. Annual Review of Information Science and Technology 41(1): 609-641.

Packer K and Webster A (1996) Patenting culture in science: Reinventing the scientific wheel of credibility. Science, Technology \& Human Values 21(4): 427-453.

Patel N (1973) Collaboration in the professional growth of American sociology. Social Science Information 12: 77-92.

Paul-Hus A, Mongeon P, Sainte-Marie M and Larivière L (2017) The sum of it all: revealing collaboration patterns by combining authorship and acknowledgements. Journal of Informetrics 11(1): 80-87. DOI: 10.1016/j.joi.2016.11.005 
Paul-Hus A, Desrochers N and Costas R (2016) Characterization and description of funding acknowledgement data in Web of Science: Key issues in their consideration as a research tool. Scientometrics 108(1): 167-182. DOI :10.1007/s11192-016-1953-y

Piwowar H (2013) Altmetrics: Value all research products. Nature 493(7431): 159-159.

Piwowar H and Priem J (2013) The power of altmetrics on a CV. Bulletin of the American Society for Information Science and Technology 39(4): 10-13.

PLOS Blogs http://blogs.plos.org/plos/2016/07/author-credit-plos-and-credit-update/

PLOS Journals (n.d.) Authorship. Available at: http://journals.plos.org/plosone/s/ethicalpublishing-practice\#loc-authorship (accessed 9 August 2016).

Pontille D (2001) L'auteur scientifique en question: pratiques en psychologie et en sciences biomédicales. Social Science Information 40(3): 433-453.

Pontille D (2004) La Signature Scientifique. Une Sociologie Pragmatique de L'attribution. Paris: CNRS Éditions.

Pontille D (2016) Signer Ensemble: Contribution et évaluation en Sciences. Paris: Economica.

Priem J (2014) Altmetrics. In: Cronin B and Sugimoto CR (eds) Beyond Bibliometrics: Harnessing Multidimensional Indicators of Performance. Cambridge, MA: MIT Press, pp. 263-287.

Priem J, Piwowar HA and Hemminger BM (2012) Altmetrics in the wild: Using social media to explore scholarly impact. arXiv preprint arXiv:1203.4745. 
Priem J, Taraborelli D, Groth P and Neylon C (2010) Altmetrics: A manifesto. Retrieved from http://altmetrics.org/manifesto/

Quan-Haase A, Martin K and McCay-Peet L (2015) Networks of digital humanities scholars: The informational and social uses and gratifications of Twitter. Big Data \& Society 2(1). DOI: 10.1177/205395171558941.

Quan-Haase A, Suarez JL and Brown DM (2015) Collaborating, connecting, and clustering in the humanities: A case study of networked scholarship in an interdisciplinary, dispersed team. American Behavioral Scientist 59(5): 565-581.

Reinhardt W, Ebner M, Beham G and Costa C (2009) How people are using Twitter during conferences. Creativity and Innovation Competencies on the Web. Proceedings of the 5th EduMedia, 145-156.

Rennie D, Yank V and Emanuel L (1997) When authorship fails: A proposal to make contributors accountable. Jama 278(7): 579-585.

Rigby, J (2011) Systematic grant and funding body acknowledgement data for publications: new dimensions and new controversies for research policy and evaluation. Research Evaluation 20(5): 365-375.

Rigby J (2013) Looking for the impact of peer review: Does count of funding acknowledgements really predict research impact? Scientometrics 94(1): 57-73.

Rong XL, Grant L and Ward KB (1989) Productivity of women scholars and gender researchers: Is funding a factor? The American Sociologist 20(1): 95-100. 
Ross K, Fountaine S and Comrie M (2015) Facing up to Facebook: Politicians, publics and the social media (ted) turn in New Zealand. Media, Culture \& Society 37(2): 251-269.

Rowlands I, Nicholas D, Russell B, Canty N and Watkinson A (2011) Social media use in the research workflow. Learned Publishing 24(3): 183-195.

Shuai X, Pepe A and Bollen J (2012) How the scientific community reacts to newly submitted preprints: Article downloads, twitter mentions, and citations. PloS ONE 7(11): e47523.

Sismondo S (2009) Ghosts in the machine: Publication planning in the medical sciences. Social Studies of Science 39(2): 171-198.

Sugimoto C, Hank C, Bowman T and Pomerantz J (2015) Friend or faculty: Social networking sites, dual relationships, and context collapse in higher education. First Monday 20(3).

Sugimoto CR., Work S, Larivière V and Haustein S (forthcoming). Scholarly use of social media and altmetrics: A review of the literature. Journal of the Association for Information Science and Technology. Retrieved from: https://arxiv.org/abs/1608.08112

Tenopir C, Volentine R and King DW (2013) Social media and scholarly reading. Online Information Review 37(2): 193-216. 
The Lancet (n.d.) Statements, permissions, and signatures - Role of the funding source. Retrieved from http://www.thelancet.com/lancet/information-for-authors/statementspermissions-signatures\#role-of-funding-source

Thelwall M and Wilson P (2015) Mendeley readership altmetrics for medical articles: An analysis of 45 fields. Journal of the Association for Information Science and Technology 67(8): 1962-1972.

Thelwall M., Vaughan L and Björneborn L (2005) Webometrics. ARIST 39(1): 81-135.

Viney I (2013) Altmetrics: Research council responds. Nature 494(7436): 176-176.

Waltman L and Costas R (2014) F1000 recommendations as a potential new data source for research evaluation: a comparison with citations. Journal of the Association for Information Science and Technology 65(3): 433-445.

Wang J and Shapira P (2011) Funding acknowledgement analysis: an enhanced tool to investigate research sponsorship impacts: the case of nanotechnology. Scientometrics 87(3): 563-586.

Weber NM and Thomer AK (2014) Paratexts and documentary practices: Text mining authorship and acknowledgment from a bioinformatics corpus. Examining Paratextual Theory and its Applications in Digital Culture, 84-109.

Weingart P (2005) Impact of bibliometrics upon the science system: inadvertent consequences? Scientometrics 62(1): 117-13 
Wilsdon J, Allen L, Belfiore E, Campbell P, Curry S, Hill S, et al. (2015) The metric tide: Report of the independent review of the role of metrics in research assessment and management.

Wouters PF (1999) The citation culture. University of Amsterdam

Wouters P and Costas R (2012) Users, narcissism and control: Tracking the impact of scholarly publications in the 21st century. Utrecht: SURFfoundation, pp. 847-857.

Wray KB (2006) Scientific authorship in the age of collaborative research. Studies in History and Philosophy of Science Part A 37(3): 505-514.

Zahedi Z, Costas R and Wouters P (2014) How well developed are altmetrics? A crossdisciplinary analysis of the presence of 'alternative metrics' in scientific publications. Scientometrics 101(2): 1491-1513.

Zuckerman HA (1968) Patterns of name ordering among authors of scientific papers: A study of social symbolism and its ambiguity. American Journal of Sociology, 276291. 